\title{
Testimonialista Pedagogues: Testimonio Pedagogy in Critical Multicultural Education
}

\author{
Yvonne Pilar El Ashmawi \\ Loyola University Chicago \\ U. S. A. \\ Ma. Eugenia Hernandez Sanchez \\ Universidad Autonoma de Ciudad Juarez \\ Mexico \\ Dr. Judith Flores Carmona \\ New Mexico State University \\ U.S. A.
}

\begin{abstract}
Teacher educators employ a variety of approaches to multicultural education. This article describes how we have our students grapple with their positionalities, to socially locate themselves and then to question the how and why of what they learned by employing testimonio, a genre of qualitative research that has its epistemological roots in Chicana feminist thought, as pedagogy. We discuss how we use testimonio in our classes and how students can use the process of creating and sharing their testimonios to cultivate a multicultural education (MCE) perspective and begin crafting their own culturally relevant pedagogy.
\end{abstract}

KEYWORDS: Testimonio Pedagogy, Multicultural Education, Testimonio, Teacher Education, Culturally Relevant Pedagogy

What is Multicultural Education?

Teacher Positionality

Testimonio as Pedagogy in the Multicultural Education Classroom Testimonio in the Multicultural Education Classroom

Testimonio Learning Activities in the Multicultural Education Classroom

Discussion

Conclusion

References

Author Contact

Social justice is the primary goal of multicultural education (Au, 2009; Darder, 1991; Gay, 2010; Ladson-Billings, 1994; Macedo; 1994; Nieto, 2000; Nieto, 2006; Sleeter, 2005; Wilhelm; 1998). Teacher preparation programs that offer multicultural education courses to their students do so with the intention that graduates will leave the program with a commitment to enacting a culturally 
responsive pedagogy (CRP) once they are teachers. Considering how to adequately address the complexity of theories and innumerable strategies that constitute a multicultural perspective and culturally responsive pedagogy in one semester feels overwhelming. Is there a way to teach everything there is to know about multicultural education in one course? Clearly, the answer is no.

As teacher educators who teach multicultural education courses, we have wondered about how to adequately prepare students to go out in schools and communities both knowledgeable of and willing to engage in CRP that attends to the needs of all students, including those who have been historically marginalized. We seek to strengthen the preparation of teachers for diverse learners by cultivating a multicultural perspective that "sticks" and remains relevant when it matters - with their own students. In this article, we share how we utilize a testimonio pedagogy in our courses to cultivate an MULTICULTURAL EDUCATION perspective that grounds our students' understanding of the ways in which their embodied social identities have contoured their own educational experiences so that they can better understand the need for employing a culturally responsive pedagogy in their teaching practice.

We first delineate multicultural education, drawing from the scholarship and building on the framework from our experiences teaching in Chicago, USA, Ciudad Juarez, Mexico, and New Mexico, USA. We also situate ourselves-our positionality and our pedagogy. After sharing how we employ testimonio pedagogy in our respective courses, we conclude by sharing how testimonio pedagogy can support students in cultivating a multicultural education perspective and taking steps towards developing their own culturally responsive pedagogy.

\section{What is Multicultural Education?}

Teacher preparation programs employ a variety of approaches to multicultural education courses. Enid Lee defines multicultural education as a perspective; its purpose "is to help us deal equitably with all the cultural and racial difference that you find in the human family" (cited in Au, 2009, p. 10). Recognizing multicultural education as a perspective rather than solely content, we do not expect that we will teach everything there is to know about how to be multicultural in the duration of a semester. Our intent is to work from a framework for multicultural education that can effect social change, one that places an "emphasis on the sociopolitical context of education and a rejection of multicultural education as either a superficial adding of content to the curriculum, or alternatively, as the magic pill that will do away with all educational problems" (Nieto, 2000, p. 304). Again, such a perspective requires that we look beyond merely addressing content, to employing a pedagogy that allows students to delve deeply into their own underlying beliefs about themselves and the world around them. Students and the instructor must be willing to engage in critical reflexivity where we all engage in exploring how our privileged and marginalized identities inform our work in the classroom and in society (Sleeter \& Flores Carmona, 2017). 
Conceptualizing multicultural education as a perspective and theoretical framework that shapes curriculum and pedagogy creates space for understanding multicultural education as an ongoing process. Nieto (2000) argues that multicultural education should be a process of comprehensive school reform with seven basic characteristics: it is anti-racist, it is basic, it is important for all students, it is pervasive, its goal is social justice, it is a process, and it is critical pedagogy (Nieto, 2000). As teacher educators, we seek to cultivate these understandings in our students so they can bring them to life in their future classrooms. While we seek to actively address all seven characteristics in our courses, we emphasize that multicultural education is fundamentally and explicitly anti-racist, it is important for all students, and its goal is social justice. The aim of engaging students in cultivating a critically multicultural perspective is so that they become willing to engage in CRP in their own classrooms. Such pedagogy involves "developing students academically, a willingness to nurture and support cultural competence, and the development of a sociopolitical or critical consciousness" (Ladson-Billings, 1995, p. 483). The deeper we dive into our course, the more our students come to see that enacting a culturally relevant pedagogy in real life involves a lasting commitment on their part to social justice, and that both the cultivation and implementation of such a pedagogy is a process.

Multicultural education is anti-racist in that it pays attention to all areas in which "some students are favored over others: the curriculum, choice of materials, sorting policies, and teachers' interactions and relationships with students and their families" (Nieto, 2000, p. 306). Multicultural education works explicitly and affirmatively to combat racism and seeks to expose discriminatory practices in schools. This antiracist stance is the cornerstone of our work with students. It is also in stark contrast to the foods, fun, and festival model of diversity. LadsonBillings (1994) further explains that teachers who are sincerely committed to multicultural education cannot be satisfied with models that consider diversity only in limited terms. Such a perspective positions attention to students' culture as simply short breaks in the "real curriculum" in which students (and sometimes families) spend time preparing for an all-school activity to honor different cultural backgrounds, but when the event is over, everything goes back to the "real work" of school. As teacher educators, one key aspect of our work is to ensure that students look beyond the trappings of culture to interrogate dynamics of power (Darder, 1991). A curriculum for social justice would include activities that encourage thinking "in more inclusive and expansive ways, reflecting on what we learn, and applying that learning to real situations" (p. 314), particularly about real world issues related to poverty, discrimination, xenophobia, or war, for example.

Unfortunately, multicultural education is often seen as being only for Students of Color. This is particularly true when the emphasis is on diversity rather than social justice or inclusion. However, Nieto (2000) points out that "all students are mis-educated to the extent that they receive only a partial and biased education" (p. 311). It is not only Students of Color who suffer when the curriculum is centered on dominant perspectives. White students and Students of Color need a more honest and complete view of history that includes multiple perspectives. Nieto explains that students from dominant groups may need multicultural 
education more than other students because they have been educated to feel "that their ways of living, doing things, believing, and acting are the only acceptable ways" (p. 312). This is problematic because it reinforces the dominant narrative and, by doing so, makes achieving social change more challenging.

Thus far we have defined multicultural education as a perspective that informs our teaching practice. The cornerstone of this perspective is a curriculum and pedagogy that is explicitly antiracist and actively engaged in working towards social justice and equity for all students. We want our students to come to see multicultural education as a perspective and an action-an ongoing process that requires both a liberatory stance and a critical approach. It is imperative that teacher educators develop a pedagogy that engages future teachers with these ideas in ways that will stay with them long after the course is over. Indeed, even for us, as the instructors of MCE courses, this work is ongoing, and we continually reflect upon how our positionality informs our praxis.

\section{Teacher Positionality}

One vital entry point into cultivating a multicultural perspective in future teachers is to support them in beginning to recognize their own positionality in the cultural milieu. Sensoy and DiAngelo (2012) define positionality as "the recognition of where you stand in relation to others in society and how it shapes what you can see and understand" (p. 187). If our students are to engage in truly anti-racist, anti-discriminatory pedagogies, they must first be aware of how our identities shape our worldview. This is essential because when we recognize how we are influenced by our lived experiences as gendered, raced, and classed beings, for example, we open ourselves up to the possibilities of understanding others. Doing so allows us to become better equipped to change our perspectives when they are based on stereotypes and misinformation.

An additional component of teacher positionality is that teachers reflect critically on the power dynamics between them and their students. For teachers to engage in more equitable power dynamics with their students, they must be willing to address power and authority in their own lives (Darder, 1991; Sensoy \& DiAngelo, 2012). They must reflect on their positionality, their lived experiences with power and authority, and how those experiences have shaped their teaching practice. Recognizing where one is situated in relation to larger structures of power can also help us learn about ourselves and better understand others. Thus, as teacher educators we have sought to employ a pedagogy that will facilitate students' learning about themselves, about others, and about how our embodied social identities impact how we are perceived and received in society. However, we wanted to do more than simply have students tell their story.

We have students grapple with their positionalities, to socially locate themselves and then to question the how and why of what they learned. From that point we can move toward supporting students in becoming teachers invested in 
holding a multicultural stance and creating a classroom practice that works towards social justice. We recognized the value of delving deeply into their lived experiences to achieve this, and thus we turned to employing testimonio as pedagogy in our MCE classrooms.

\section{Testimonio as Pedagogy in the Multicultural Education Classroom}

Testimonio is a genre of qualitative research that has its epistemological roots in Chicana feminist thought (Anzaldúa, 1990; Delgado Bernal, Burciaga, \& Flores Carmona, 2012; Latina Feminist Group, 2001; Prieto \& Villenas, 2012; Saavedra \& Pérez, 2012; Saldaña, Castro-Villareal \& Sosa, 2013; Sánchez \& Ek 2013). It is defined as "a narrative told by someone who has had firsthand experience with political repression, violence, or other forms of oppression" (Elenes, 2013, p. 137). Testimonialistas (participants who agree to share their stories and engage in the process of testimonio) share their lived experiences to bring forward the lives of those who are from communities that have been marginalized. In this sense, it is a form of counter-storytelling.

We believe very strongly that our students' stories matter-all of them. Each student's story carries generational memories, geographical journeys, and aspirational (Yosso, 2005) possibilities. A student's story is also the story of a family, of a community, and often of contested cultural spaces inside and beyond the school. More important, a student's act of sharing his/her/their story can represent an alternative perspective for commonsensical naturalized uncontested knowledge. Thus, the importance of the student's story in his/her/their own words becomes a fundamental value of testimonio pedagogy. Listening to testimonios becomes a learning opportunity for all in the classroom. However, testimonio is more than story-telling.

Delgado Bernal, Burciaga, and Flores Carmona (2012) explain that testimonio "is and continues to be an approach that incorporates political, social, historical, and cultural histories that accompany one's life experiences as a means to bring about change through consciousness-raising" (p. 364). Thus, it is different from storytelling or narrative in that the testimonialista is encouraged to share her testimonio as an explicitly political act that denounces systemic oppression and inspires social justice activism in both the testimonialista and the listener. The testimonialista is asked not only to share her stories, but also to make meaning from them, to theorize about their significance, and to use them to reflect deeply about how she wants to advocate for social justice considering what she has learned through her testimonio. The listener is asked to bear witness to what has been shared, and to enact solidarity, become an ally to the testimonialista in advocating for social justice.

Testimonio is not only a research method and methodology; it is also pedagogy in that it "can inform research and teaching while helping those living on or in the margins make sense of and heal fragmented lives" (Saavedra \& Pérez, 2012 , p. 431). The practice of testimonio, then, is meant to be reciprocal and 
communal. It is reciprocal because the researcher-educator does not simply take what has been shared for their own use. Instead, the testimonialista shares her expertise about her life and her community's collective experience.

Delgado Bernal and Villalpando (2002) explain that knowledge not from traditional epistemic sources is often devalued and marginalized. Beyond adding to classroom knowledge, testimonio is a way of contesting what counts as knowledge and whose knowledge counts in schools. Indeed, Apple (2012) explains that education is a "site of conflict about the kind of knowledge that is and should be taught, about whose knowledge is 'official' and about who has the right to decide both what is to be taught and how teaching and learning are to be evaluated" (kindle location 66). Epistemology matters, then, because what makes it into curriculum is a product not only of a body of knowledge and who produced it, but it is also about asking what is left out.

The process of testimonio, of actively listening to our lived experiences, is a pedagogy that embraces a testimonialista's funds of knowledge (González, Moll, \& Amanti 2005). Funds of knowledge are those "historically accumulated and culturally developed bodies of knowledge and skills essential for household or individual functioning and well-being" (p. 72). When we elicit testimonios from our students, we will learn about students' familial-communal experiences of survival and resistance and how they have experienced oppression in schools and in society.

We have employed testimonio pedagogy by having students reflect critically on their own educational experiences through our assignments. Their educational narrative, for example, asks students to share difficult experiences of "cultural dissonance [which] highlight the contradictions we experienced in the institutions of family and education, particularly along markers of race/ethnicity, class, gender, sexuality, immigration status and experience, and language" (Prieto \& Villenas, 2012, p. 416). As students begin to share their experiences, they quickly discover that their positionality is complex, that the intersectionalities of their social identities contain experiences of oppression, complicity, resistance, and conformity.

Recognizing the complexity of their own experiences creates space for raising critical consciousness and encourages students to see how, just as their own social identities are complex and multidimensional, so too are the social identities of others. Sharing testimonios is a way to counter master-narratives that students have internalized along their educational trajectories. When we all share our testimonios, we offer new ways of theorizing the world, and we support each other in validating our lived experiences as legitimate sources of knowledge (Delgado Bernal, 2002).

Testimonio is an inherently political act because it seeks to compel the testimonialista as well as the reader/listener to action (Anzaldúa, 1990; Delgado Bernal, Burciaga, \& Flores Carmona, 2012; Latina Feminist Group, 2001; Saavedra \& Pérez, 2012; Prieto \& Villenas, 2012; Saldaña, Castro-Villareal, \& Sosa, 2013; Sánchez \& Ek 2013). Anzaldúa (1990) explains that naming our oppression is a political act because when we "transform silence into language, a 
woman transgresses" (p. xxii). She adds that when we do speak, our voices are often "drowned out by white noise, distance and the distancing of others who don't want to hear" ( $p$. xxii). Thus, speaking one's lived experience is a powerful form of political resistance. In addition to the personal political act, sharing one's testimonio is an opportunity to rally for solidarity. Having named the oppression(s) experienced by her and her community, the testimonialista is asked what her community needs, and how we can be allies in the struggle. The testimonialista then is the expert about her own pain and her liberation.

Testimonio pedagogy moves us toward an understanding of suffering, not as an individual experience but as a communal process of teaching and learning. This type of pedagogy allows a naming of ourselves, naming of our pain, naming of feelings and biases. The way that people read, connect, engage, draw, and get inspired to share legitimizes the theory of testimonio - legitimizes organic knowledge(s) and an organic method of merging theory and practice. The feminista praxis of listening to stories of struggle, survival, resistance, and oppression forces the student and teacher to come inside the classroom as "whole" beings (Flores Carmona \& Luciano, 2014, p. 89). The process of engaging in testimonio allows students to explore their own lived experiences and enact agency around their own liberation, while also learning about the lived experiences of others, and building political solidarity in the struggle for social justice.

\section{Testimonio in the Multicultural Education Classroom}

As teachers from different Latinidades (Latina Feminist Group, 2001), we affirm our agency by sharing our teaching stories and asserting that "despite the pressure to work in solitude in higher education, testimonio as critical pedagogy encouraged a co-construction of knowledge and closer working relationship between student and teacher" (Burciaga \& Cruz Navarro, 2015, p. 39). Since 2010, the third author has been teaching and incorporating testimonio pedagogy in her teaching - whether in teaching an actual course on testimonio or in a required MCE course for undergraduates in teacher education. The first and second author began teaching MCE courses with her guidance. The three of us implement testimonio pedagogy, and we learn from each other, bear witness to the challenges we encounter teaching MCE, and make meaning from our experiences. By implementing testimonio pedagogy, we are choosing to make our classrooms a window into our communities to see how our lives are interconnected. By sharing with each other, we come to see and hear each other and cultivate an ally-ship with our students. Thus, the process of engaging in testimonio in our courses not only helps our students to learn about MCE as a perspective that is explicitly antiracist and anti-bias, but also helps us learn firsthand from each other how the systems of oppression impact/affect all of us. In the next section, two of us briefly share our positionality and how we implement testimonio pedagogy in our distinct classroom settings. We build on the work of Flores Carmona and Luciano (2014) and create a bridge between testimonio pedagogy and critical MCE. 


\section{Yvonne}

I am a Chicana, Chamorro, and White Muslim American woman. I consider myself Chicana: I see myself in my roles as mother, grandmother, wife, researcher, and instructor as inherently and explicitly a political activist. After teaching middle and high school English for many years, I became a college instructor of MCE while working on my dissertation. I am currently a secondary English teacher educator, and I continue to teach an MCE course. In both institutions where I have taught MCE, the course is a mandated part of the curriculum for all students, and so they arrive to my class holding various amounts of willingness and openness to cultural critique and personal exploration.

\section{Written Testimonio Embodied Social Identities Essay}

In my MCE course, I begin by helping students rethink their definition of theory. We often think of theory as an abstract, ultra-academic endeavor, when in fact, we theorize about lots of things in our day-to-day life. Much of our theorizing remains obscured from us because both our self-knowledge and our intuition are not received or perceived to be important, not even to ourselves. Testimonio is a research method, methodology, and pedagogy that responds to Moraga's (1981) call for a theory of the flesh. Moraga explains that a theory of the flesh "means one where the physical realities of our lives-our skin color, the land or concrete we grew up on, our sexual longings-all fuse to create a politic born out of necessity" (p. 50). My first task is to help students see not only the value of theorizing, but the value of theorizing from the flesh, from what they have lived.

I carry this notion of theorizing throughout my course by asking students to write about their lives. The goal is to use writing as a tool to better understand ourselves and each other. Freire and Macedo (1987) called for the development in students of a critical literacy that helps them to read the word and the world. Equally important is for students to write about the world(s) they inhabit. As Christensen (2009) states, writing and talking about issues "like race, class, gender, and solidarity...takes them out of the shadow world and into the light of day, so students can understand why things are fair or unfair and how to change them" (p. 1). Writing allows students to communicate things they may not be comfortable saying aloud.

Throughout the course, the focus is on the students' educational experiences, but I also push them to think about how their experiences made an impact on their schooling. This is important, because major life events often have rippling repercussions. As we begin reading about systems of power that reproduce social injustice, students come to make deeper connections to their 
experiences. These connections are important to make since testimonios serve to bridge the contradictions embedded in our experiences (Moraga, 1981). I want my students to come to see that the intersections of their gendered, raced, and classed identities contain within them oppression and privilege. For example, if they moved schools often they can reflect about the impact of social class and the (in)visibility of systems of power that reify race and class-based oppression. Their testimonios develop depth, becoming a three-dimensional portrayal of the students' lives.

The major assignment of the course asks students to write their testimonio about how two of their embodied social identities shaped their educational experiences. However, to facilitate the writing, throughout the course I assign a series of brief informal in-class writing activities in which students begin to reflect on different aspects of their testimonio. Once they are written, the students make meaning of their testimonios of marginalization/oppression and connect them to the theories of social justice and culturally relevant pedagogy that they learn about throughout the semester. Finally, they share this reflexive testimonio as a tool that helps them shape their pedagogy.

Students get opportunities for practice; prior to this they have seldom, if ever, been asked to write about their lives and reflect on them. They connect deeply with theory, and what they are learning is a key component of testimonio, namely critical reflection and meaning-making. It is the site of the struggle. Testimonio asks them to sit with the story, to consider, to reflect, and to actively connect their personal experiences to the experiences of their community and systems of power. This process is the work of testimonio pedagogy, involving both deep intellectual and deep heart-centered work.

While writing is the medium for our testimonios, the heart of the learning activities is that I ask them to share their work with each other. They begin sharing in pairs and taking turns talking and listening. Students give feedback to each other, and in doing so they build community and create solidarity. Therefore, testimonio pedagogy is the process of making ourself visible/seen through the divulging of our stories as they connect to larger systems of power, privilege, and oppression.

\section{Ma. Eugenia}

I am a mujer fronteriza from the borderlands. I live and teach in Ciudad Juarez, Mexico, a place of contradictions where being a woman makes you vulnerable in many ways. Soy testigo, I can witness that the building of the wall has been happening since I can remember. My educational journey includes circular movements between the U.S. and Mexico. I teach MCE, analysis and creativity, and borderlands art to decolonize Western ideas about us borderlands people. Thus, my position concurs with what Fine (2009) calls "the deliberate use of theory" as an act of liberation (p. 190). In this tone, testimonio pedagogy allows 
me to recognize that Nepantla (in betweenness) feels like home. I teach to learn from students about resistance, resilience, and peaceful ways to contest oppression from within. I teach to confront my own assumptions about what students can achieve and, finally, because meaningful knowledge can lead to transformations in unequal places like the border between Mexico and the United States.

\section{Visual Educational Testimonio Timeline}

I present visual testimonio to interrogate social order. We draw from Olmos' (2011) notion of "symbolic system as a method for the understanding of aesthetic affect. Stated differently, it is necessary to analyze representations not only as references, as evocations or reflections, but as references whose particular meaning is the affective load culturally constructed" (p. 218). In these terms, we broadly define visual testimonio as symbolic metacognition rooted in Latin America ancient cultures (Gonzalez, 2014) as a response to supervivencia (beyond survival) (Olmos, 2011; Trinidad Galvan, 2015) yet attuned with current digital imagery (Benmayor, 2008). The goal of the visual testimonio is to theorize from personal experience via the validation of the students' voice by scaffolding conceptually into a discussion of intersectionality.

Visual approaches are closely related to Latin American ancient ways of testifying through symbolic representation. For example, Gonzalez (2014) has been pivotal in the cultural analysis of representing visually how we learn to forget. In her analysis of the collection of paintings titled Piraq Causa (Who is Still to Blame?) in Peru, she refers to the meaning of quelca "from the Quechua terms meaning both drawing and writing" (p. 69). In addition, Benmayor (2008) has influenced the study of visual testimonio in the United States, especially by disserting over the connection between creativity and critical thinking via digital testimonios. I concur with Benmayor's emphasis on how students "use their 'situated knowledge' - through speaking about, reflecting on, and analyzing lived experience - to produce new social/cultural/historical understandings" (p. 189). Drawing and painting with the hands forces us to slow down while drawing/thinking. It moves us from a rational verbal coherence into the possibilities of fractures and fragments of symbols; it moves us from looking at each other into looking at our multiple selves within a collective activity, and thus we begin listening to each other.

As an exercise in my multicultural analytical course, the primary objective of the visual testimonio educational timeline assignment is to think in concepts before introducing them in the form of text. The visual testimonio works by connecting three layers: at the center is the lived experience during early school years, the upper level visualizes events at the national/international/transnational level within the same range of years, and the lower level is our milieu, the community level in which family or neighborhood events are also visualized. The development of a language to interrogate the world is fundamental. However, I try 
to work in a deep understanding of form before the concepts are introduced. One of the major difficulties is to understand the perceived disconnection between lived experience and national events, for example. This is where concepts become relevant, the disconnection becomes a discussion, and social justice anti-racist language becomes necessary to make sense of how inequality has long-lasting naturalized consequences.

More importantly, conceptualizing our experience (visually and then with text) gives us the opportunity to move away from memorization of concepts into the representation of a relevant pedagogy that can address students' complexities. Thus, "testimonio pedagogy lends itself to incorporating students' epistemologies, to creating spaces of solidarity, and to connecting across our differences" (Araujo, Flores Carmona, Parra, \& Chávez Chávez, 2014, p. 22). By concentrating on the students' testimonios (using visual representations of memories) we can interrogate history through tensions by making connections between personal events and social structures.

Having taught simultaneously on both sides of the border (New Mexico, USA, and Ciudad Juarez, Mexico) has given me the opportunity to recognize the importance of the act of sharing testimonios in the classroom. Sensoy and DiAngelo (2012) poignantly state that "our beliefs need not be inherently true to have very real consequences" (p. 18). One of the most striking recurrent consequences during the exercise discussed is how female students from both sides of the border have learned not to show their smartness or sport abilities during their first elementary school years. Many draw, and later describe, images of times when coaches and their own parents advised them not to excel in front of their male peers. Others remember how their clothes and movements were/are monitored all the time. Male students also recall how they learn what it means to be a man and how difficult it is to maintain the assigned social construction of masculinity. Both experiences reveal the invisibility of oppression (Sensoy \& DiAngelo, 2012); by having students draw some of their lived experiences, they make oppression visible to themselves and their colleagues.

Concepts such as social construction along with our lived experience become relevant by interrogating our experiences in both, the school and homespace. While addressing key concepts and discussions on gender inequality, for example, we draw from Chicana feminisms to think in terms of transformation and to move from recognizing oppression into imagining ways to develop strategies of solidarity by recognizing shared experiences of subjugation based on gender. Cervantes-Soon's (2016) conceptualization of mujeres (women) truchas is the smartness that "allow them to navigate a hostile and precarious environment, heal from painful experiences, and self-author their identities in empowering and critical ways" (p. 7). Mujeres truchas involves "women engaged in a process of decolonization that allowed them to recognize and tap into subjugated ways of knowing to envision a different paradigm of life" (p. 7). Visual testimonio represents a curricular design to begin to decolonize the mind.

To move from traditional ways of knowing where memorization of concepts is common or even expected, we represent our experience with visual symbols or 
simple drawings loaded with meaning and with endless possibilities to theorize. I echo Duncum's (2006) idea that "visual culture art education creates a crossroads - an intersection - of MCE and postmodernism that could bring about tangible, recognizable curricular change among art education communities" (as cited in Nieto et al., 2008, p. 187). Consequently, presenting a visual testimonio of our early encounter with education at school represents the path to inquire how we learn which knowledge and behaviors were regarded as valid and which ones were seen as anecdotal. Therefore, employing testimonio pedagogy in the borderlands has allowed me to present a critical approach to understanding the key concepts of MCE in Mexico and in the United States.

\section{Testimonio Learning Activities in the Multicultural Education Classroom}

While across the various sections of the required MCE course instructors are required to have students reflect on the ways in which their social identities contoured their own experiences in and out of school, how each instructor approaches this varies. Each of the authors engages in ongoing discussions and learning activities throughout the semester designed to support students in making connections between their lived experiences, the theories presented via the course readings, and their future pedagogy. Below are brief descriptions of example assignments given by both authors.

\section{Yvonne: Social Identity Paper}

Our work throughout the semester is to develop a deeper and more nuanced understanding of the impact of social issues such as race, ethnicity, gender, sexual orientation, age, language, citizenship status, and religion on and within schools and classroom. As the culminating assignment for the course, students reflect on their positionality as student and future teacher by writing a fiveto seven-page paper. In the paper they discuss the impact of two or three of their embodied, intersecting social identities on their own educational experiences, how these experiences reflect the theories we have studied throughout the course, and how they will use their experiences to inform their developing pedagogy. Students are required to cite four or more of our course readings.

The idea prompts for the paper are designed to engage students in theorizing from their own flesh, from the body. They are encouraged to revisit our class discussions and journals, as well as their educational timelines, which were developed earlier in the semester. Students are also asked to consider the following questions: What key (or perhaps on the surface seemingly minor, yet profound) experiences in school impacted how you felt about school, how others treated you, or your sense of self? How were these experiences reflective of your 
social identities? How do these experiences connect to the theories we have read about throughout the semester? Students are required to conclude the paper with a discussion of how their theorizing about their own experiences in light of the readings we have done about equity in education will inform their future pedagogy. To do that, students are encouraged to consider: What are the beliefs you are taking with you into your future classroom? How will these beliefs be reflected in your pedagogy? Students are expected to include two or three specific examples of ways of being or learning activities that they will utilize as part of their own equity pedagogy.

\section{Ma. Eugenia: Visual Educational Narrative}

The visual educational narrative addresses the way we learn to learn. The goal is to imagine diverse ways of approaching knowledge and critical thinking. We begin by provoking a class dialogue to discuss our early years in elementary school. To elicit students' memories, I ask students to bring a picture or a copy of a document of elementary school years, color pencils, and anything they consider can work towards the development of the timeline such as a family picture, piece of textile of their uniform, or a drawing of their favorite toy.

Through this assignment, we explore how important our memories are in order to understand the way we learn to relate to the construction of knowledge, and to those in charge of selecting which knowledge was important and how to implement it. I, as instructor, share my own personal story in a way that makes evident the invisibility of socialization (Sensoy \& DiAngleo, 2012) in the process of learning class content. I also emphasize how the invisibility of socialization structures the relation between curriculum content and social location (Kirk \& Okazawa, 2013). Through students' sharing and discussion during the visual educational narrative, as a class we begin the work of using concepts by connecting them to student's personal experience, which in turn is connected to the larger contexts of education and society.

The above examples of learning activities are offered at different points in our respective courses. However, both invite students to reflect on and make meaning of their lived experiences. These reflections then become the catalyst for considering how these understandings about the impact of social identities on their own lives will inform their future pedagogy. Thus, while employing different tools, written and visual expression, both learning activities help students develop their own testimonios.

\section{Discussion}

For the three of us, implementing a testimonio pedagogy in our courses has been a powerful tool that supports our students' cultivation of an MCE perspective 
that sustains them and shapes their pedagogy in their own future classrooms. Although our implementation of testimonio as pedagogy utilizes different mediums, we recognize that developing and then sharing their testimonios allows students to see their experiences as simultaneously unique, a reflection of their familialcommunal realities, and interwoven into the story of the larger society and nationstates. This capacity to hold each of these dimensions of lived experience as inherently valuable, relevant, and important is a key component of cultivating an MCE perspective that values social justice, for the individual and the collective, and that crosses borders.

In addition to utilizing testimonio pedagogy to support perspective taking, we also use it to foster solidarity in our classrooms and communities. It is important to note that the end goal is to use the process of developing (in writing or visually) one's testimonios to engage in active listening and to move the class to form allyships and take action. We want students to begin crafting an action plan wherein they develop strategies to implement culturally relevant teaching practices that promote academic achievement, cultural competence, and political consciousness raising.

MCE and testimonio pedagogy is a natural connection and praxis for us, as it should be for critical pedagogues in the United States and beyond because it cultivates a critical multicultural perspective. Testimonio pedagogy in the MCE classroom involves the recognition not only of systems of oppression but, perhaps more importantly, the recognition of how we internalize such a system.

To encourage the difficult conversation of one's own oppression, the development of a language to name experiences of discrimination, stigmatization, and resistance becomes crucial. As teacher educators, our role is being the interlocutors between the students' educational narrative and our own, to elicit solidarity as a part of our teaching and learning. Thus, the most vulnerable part of our educational journeys (at home and at school) allows us to open a reflective conversation based on lived experience and to theorize it from our own circumstance. McLaren (2009) asserts that critical pedagogy "asks how and why knowledge gets constructed the way it does, and how and why some constructions of reality are legitimated and celebrated by the dominant culture while others clearly are not" (p. 63). Thus, as our students grapple with their own testimonios, the theories put forth in our courses about how knowledge is constructed and whose knowledge has power come into sharper focus through their own lived experiences.

\section{Conclusion: Let's Continue Testimoniando in Multicultural Education}

With testimonio pedagogy in MCE we highlight, acknowledge, and listen to diverse perspectives and experiences. Indeed, we employ intentional listening that allows us to connect MCE concepts to lived experience. In the process, we are 
also engaging in an alternative co-construction of knowledge with our students, and we connect our lived realities to and with the social structures. We do not give voice through our testimonio assignments; rather, our students have voices that we welcome into the class via testimonio pedagogy. This distinction is important to us as social justice-oriented teacher educators. We are not giving agency, voice, or power; rather, we are creating spaces where it is safe and empowering for our students to fully embody their already rich voices and where they are the holders and producers of knowledge (Delgado Bernal, 2002).

As teacher educators, we use testimonios to inquire about the collective experience of oppression so as to systematically learn about the community we serve and become close allies to those communities and each other. We cultivate ally-ships by guiding students to begin crafting their own culturally relevant teaching pedagogy — based on the invoked self-reflexivity in writing or doing visual testimonios. We work on ensuring that testimonio as practiced in our classroom demonstrates our purpose to "carefully craft truth-telling that is polyphonous in its voice and political in its intent" (Lugones, 2003, p. 7). As students craft their testimonios, we ask guiding questions that help them to connect the dots between what they have experienced, how this connects to holding an MCE perspective, and how they will act in their capacity as community members and educators considering their own experiences. As they bear witness to the testimonios of their colleagues, they are challenged to consider how they will serve as allies to the communities they serve and to our society-whether in the U.S. or in Mexico.

The goal of MCE is social justice, and the goal of testimonio is to create and foster relationships of solidarity and to take action. If students are to employ a culturally responsive pedagogy in their own classrooms, they must have a clear understanding of the theoretical frameworks of MCE, but more importantly come to hold an MCE perspective on the need for supporting all students to achieve academically, become culturally competent, and raise critical and political consciousness (Ladson-Billings, 1994). Therefore, we employ testimonio, as it represents an "opportunity to reflect upon our past as we develop new aspirations [and] has provided opportunities to turn challenges into possibilities" (Burciaga \& Cruz Navarro, 2015, p. 39). One possibility and intention of testimonio pedagogy is to cultivate the cultural competence and political consciousness-raising that we want our students to develop in their future classrooms. Indeed, by acknowledging, writing and disseminating testimonios in our MCE courses, we are engaging in a pedagogy of social justice that transforms the pedagogues and future teachers.

\section{References}

Araujo, B., Flores Carmona, J., Parra, J., \& Chávez Chávez, R. (2014). Digital explorations along the borderlands: Transfronterizo youth, testimonio, and personal learning networks. International Journal of Information 
Communication Technologies and Human Development (IJICTHD), 6(2), 16-31.

Anzaldúa, G. (1990). Making face, making soul: Creative and critical perspectives by feminists of color $=$ Haciendo caras. San Francisco, CA: Aunt Lute Books.

Apple, M. (2012). Ideology and curriculum (3rd ed.). New York, NY: RoutledgeFalmer.

Au, W. (2012). Critical curriculum studies: Education, consciousness, and the politics of knowing. New York, NY: Routledge.

Benmayor, R. (2008). Digital storytelling as signature pedagogy for the new humanities. Arts and Humanities in Higher Education, 7(2), 188-204.

Burciaga, R., \& Cruz Navarro, N. (2015). Educational testimonio: Critical pedagogy as mentorship. New Directions for Higher Education, 171(fall), 33-41.

Cervantes-Soon, C. (2016). Mujeres_truchas: Urban girls redefining smartness in a dystopic global South. Race, Ethnicity and Education, 19(6),1-14.

Christensen, L. (2009). Teaching for joy and justice: Re-imagining the language arts classroom. Milwaukee, WI: Rethinking Schools Publication.

Darder, A. (1991). Culture and power in the classroom: A critical foundation for bicultural education. New York, NY: Bergin \& Garvey.

Delgado Bernal. D. (2002). Critical race theory, Latino critical theory, and critical raced-gendered epistemologies: Recognizing students of color as holders and creators of knowledge. Qualitative Inquiry, 8(1), 105-126.

Delgado Bernal, D., Burciaga, R., \& Flores Carmona, J. (2012). Chicana/Latina testimonios: Mapping the methodological, pedagogical, and political. Equity \& Excellence in Education, 45(3), 363-372.

Delgado Bernal, D., \& Villalpando, O. (2002). An apartheid of knowledge in academia: The struggle over the "legitimate" knowledge of faculty of color. Equity and Excellence in Education, 35(2), 169-180.

Elenes, C. (2013). Nepantla, spiritual activism, new Tribalism: Chicana feminist transformative pedagogies and social justice education. Journal of LatinoLatin American Studies (JOLLAS), 5(3), 132-141.

Fine, M. (2009). Epilogue. In J. Anyon et al. (Eds.), Theory and educational research. Toward critical social explanation (pp. 179-196). New York, NY: Routledge.

Flores Carmona, J., \& Luciano, A. M. (2014). A student-teacher testimonio: Reflexivity, empathy, and pedagogy. In J. Flores Carmona \& K. Luschen (Eds.), Crafting critical stories: Toward pedagogies and methodologies of collaboration, inclusion \& voice (pp. 75-92). New York, NY: Peter Lang. 
Freire, P., \& Macedo, D. (1987). Literacy: Reading the word and the world. Westport, CN: Routledge.

Gay, G. (2010). Culturally responsive teaching theory, research, and practice. New York, NY: Teachers College Press.

González, N., Moll, L., \& Amanti, C. (2005). Funds of knowledge: Theorizing practice in households, communities, and classrooms. Mahwah, $\mathrm{NJ}$ : L. Erlbaum Associates.

Gonzalez, O. (2014). Testimonio and secrecy in a traumatic past. The "times of danger" in the visual art of Sarhua. Journal of Global and Historical Anthropology, 69, 65-83.

Kirk, R., \& Okazawa, M.(2013). Identities and social location. M. Adams, W.J. Blumenfeld, C. Casteñeda, H. Hackman, M. L. Peters, \& X. Zúñiga (Eds.), Readings for diversity and social justice (pp. 9-14). New York, NY: Routledge.

Ladson-Billings, G. (1994). What we can learn from multicultural education research. Educational Leadership, 51(8), 22-26.

Ladson-Billings, G. (1995). Toward a theory of culturally relevant pedagogy. American Educational Research Journal, 32(3), 465-491. doi:10.2307/1163320

Latina Feminist Group. (2001). Telling to live: Latina feminist testimonios. Durham, NC: Duke University Press.

Lugones, M. (2003). Pilgrimages/Peregrinajes: Theorizing coalition against multiple oppressions. Lanham, MD: Rowan

McLaren, P., Macrine, S., \& Hill, D. (Eds). (2009). Revolutionizing pedagogy: Educating for social justice within and beyond global neo-liberalism. London, UK: Palgrave Macmillan.

Macedo, D. (1994). Literacies of power: What Americans are not allowed to know. Boulder, CO: Westview Press.

Moraga, C. (1981). This bridge called my back: Writings of radical women of color ( $2^{\text {nd }}$ ed.). New York, NY: Kitchen Table: Women of Color Press

Nieto, S. (2000). Language, culture, and teaching critical perspectives for a new century. New York, NY: Routledge.

Nieto, S. (2006). Teaching as political work: Courageous and caring teachers. Presented at The Longfellow Lecture, Bronxville, NY. New York: Sarah Lawrence College.

Nieto, S., Bode, P., Kang, E., \& Raible, J. (2008). Identity, community, and diversity: Retheorizing multicultural curriculum for the postmodern era. In F. Connelly, M. He, \& J. Phillion (Eds.), The SAGE handbook of curriculum and instruction (pp. 176-198). Thousand Oaks, CA: SAGE Publications,. 
Olmos Aguilera, M. (2011). Sistemas de representacion: Lenguage y mitologia [Systems of representation: Language and mythology]. In Miguel O. A., El Chivo encantado: La estetica del arte indigena en el noroeste de Mexico [The enchanted goat: Northwestern Mexico art aesthetics] (pp. 217-251). Tijuana, B.C., Mexico: COLEF.

Prieto, L., \& Villenas, S.A (2012). Pedagogies from nepantla: Testimonio, Chicana/Latina feminisms and teacher education classrooms. Equity \& Excellence in Education, 4(5), pp. 411-429.

Saavedra, C. M., \& Pérez, M. (2012). Chicana and Black feminisms: Testimonios of theory, identity, and multiculturalism. Equity \& Excellence in Education, 45(3), 430-443. doi:10.1080/10665684.2012.681970

Saldaña, L., Castro-Villarreal, F., \& Sosa, E. (2013). Testimonios of Latina junior faculty: Bridging academia, family, and community lives in the academy. Educational Foundations, 27(1/2), 31-48.

Sánchez, P., \& Ek, L. D. (2013). Before the tenure track: Graduate school testimonios and their importance in our profesora-ship today. Educational Foundations, 27(1/2), 15-30.

Sensoy, O., \& DiAngelo, R. (2012). Is everyone really equal?: An introduction to key concepts in social justice education. New York, NY: Teachers College Press.

Sleeter, C., \& Flores Carmona, J. (2017). Un-standardizing curriculum: Multicultural teaching in the standards-based classroom (2nd ed.). New York, NY: Teachers College Press.

Trinidad Galvan, R. (2015). Women who stay behind. Pedagogies for survival in rural transmigrant Mexico. Tucson, AZ: University of Arizona Press.

Wilhelm, R. W. (1998). Issues in multicultural education. Curriculum Journal, 9(2), 227.

Yosso, T. (2005). Whose culture has capital? A critical race theory discussion of community cultural wealth. Race, Ethnicity and Education, 8(1), 69-91.

\section{Author Contact}

Yvonne Pilar El Ashmawi: yelashmawi@luc.edu

Loyola University Chicago, School of Education, 111. E. Pearson St, Chicago, IL 60611, USA

Ma. Eugenia Hernandez Sanchez: maru@nmsu.edu

Autonoma de Ciudad Juarez Av. Benjamin Franklin no. 4650, Zona PRONAF 32310 Cd Juárez, Chih., Mexico 
Dr. Judith Flores Carmona: judithfc@nmsu.edu

New Mexico State University, College of Education, P.O. Box 30001, MSC 3AC Las Cruces, NM 88003, USA 